\title{
Importance of measuring Bone Mineral Density in Adult Coeliac Disease Patients
}

\author{
Dr KK Desai MRCP*, Dr. RK Desai MS DNBE ${ }^{\dagger}$ and Dr. DI Hobday MD MRCP${ }^{\mp}$ \\ *Specialist Registrar, Dept. of Gastroenterology, City Hospitals Sunderland, UK \\ Clinical Fellow, Tata Memorial Hospital, Mumbai, India \\ ${ }^{\bar{T}}$ Consultant, Department of Gastroenterology, City Hospitals Sunderland, UK
}

(Received 19 December 2006 and accepted 19 March 2007)

\begin{abstract}
This study was conducted with an aim to confirm the presence of osteoporosis in patients proven to be suffering from Coeliac Disease and compare present practice in the hospital against the guidelines suggested in the published literature. Information was obtained by retrospective analysis by reviewing notes of 73 patients with coeliac disease, who are registered in the database of a busy Gastroenterology Department of Sunderland Royal Hospital. Of the total of 73 patients, 54 patients underwent a DEXA scan at diagnosis and the Osteoporosis (WHO defined criteria of T score below 2.5 SD the mean adult) was detected in 15(27.3\%) of them. 6 of the 15 patients detected to have osteoporosis were less than 53 years of age. Osteoporosis is common in patients with coeliac disease, and need regular monitoring for osteoporosis, as they are at significant risk of developing it.
\end{abstract}

KEY WORDS: Osteoporosis, Coeliac Disease, Bone Mineral Density.

\section{INTRODUCTION:}

Osteoporotic fractures are a major public health problem. ${ }^{1}$ It has been estimated in the USA the lifetime fracture risk at the age of 50 years is $40 \%$ for white females and $13 \%$ for white males, ${ }^{1}$ the major fracture sites being spine, forearm and hip. This results in considerable morbidity and mortality and rising cost including acute hospital care and long term care in home or nursing home. The estimated annual cost of Osteoporotic fractures in England and Wales is $£ 1.73$ billion. $^{2}$ Osteoporosis is a frequent complication in the course of various gastrointestinal disorders like coeliac disease, Inflammatory Bowel Disease (Especially those on steroids) and Liver Diseases. Coeliac disease is a lifelong intolerance to the gluten found in wheat, barley and rye, and some patients are also sensitive to oats. ${ }^{2}$ The disease is genetically determined, with $10 \%$ of the first-degree relatives affected. $95 \%$ of the patients with coeliac disease are human leucocyte antigen (HLA)-DQ2 or HLA-DQ8 positive. $^{3}$ Characteristically, the jejunal mucosa becomes damaged by a T-cell-mediated autoimmune response that is thought to be initiated by a 33mer peptide fragment in A2 gliadin, and patients with this disorder have raised levels of antiendomysial antibodies in their blood. ${ }^{3}$ The mechanism of underlying osteoporosis in coeliac disease is secondary to calcium malabsorption leading to increased parathyroid hormone secretion, which in turn, increases the bone turnover and cortical bone loss. ${ }^{4}$ Vitamin D malabsorption is probably of less significance. Though it has been recognised that osteomalacia may coexist in these patients, especially before treatment and may need treatment with vitamin D. In some men, there may be loss of gonadal function, as in women, may cause osteoporosis. ${ }^{4}$

Corresponding Author: Dr KK Desai, 7 Princes Meadows, Newcastle Upon Tyne, NE3 4RZ, UK, Email: drdesaikiran@yahoo.co.uk 


\section{MATHODOLOGY:}

This is retrospective analysis of patients with coeliac disease who were attending Gastroenterology clinics of the Sunderland Royal Hospital. The diagnosis of coeliac disease was based on the clinical presentation, serological evidence of presence of AntiEndomysial antibodies and characteristic histology and response to gluten withdrawal. There have been studies done to reconfirm the presence of Osteoporosis in patients with coeliac disease. $^{5-13}$ Most studies have emphasised the importance of performing DEXA scan at diagnosis, irrespective of the patient's age, sex, and race. The published literature have also suggested ways of following up these patients with DEXA scans at regular interval, depending on the status demonstrated on the first DEXA scan.
Dual energy X-ray Absorbsiometry (DEXA) Measurement: DEXA scan were performed in the medical physics department of Sunderland Royal Hospital. Bone Mineral Density (BMD) was measured at the hip and the lumbar spine, and was expressed as number of standard deviations above and below either the mean BMD of the young adult ( $\mathrm{T}$ score) or the mean BMD for the age matched controls ( $\mathrm{Z}$ score).

A BMD of 2.5SD or more below the mean are taken to be indicative of osteoporosis. ${ }^{14}$ Stratification of fracture risk is possible using BMD. The risk increases roughly two fold for each SD decline below the population mean. ${ }^{14,15}$ Hence, the endeavour about the need to evaluate the present patient management strategy based on following guidelines (Table 1):

Table 1: Summary strategy for prevention and treatment of osteoporosis in coeliac disease ${ }^{1}$

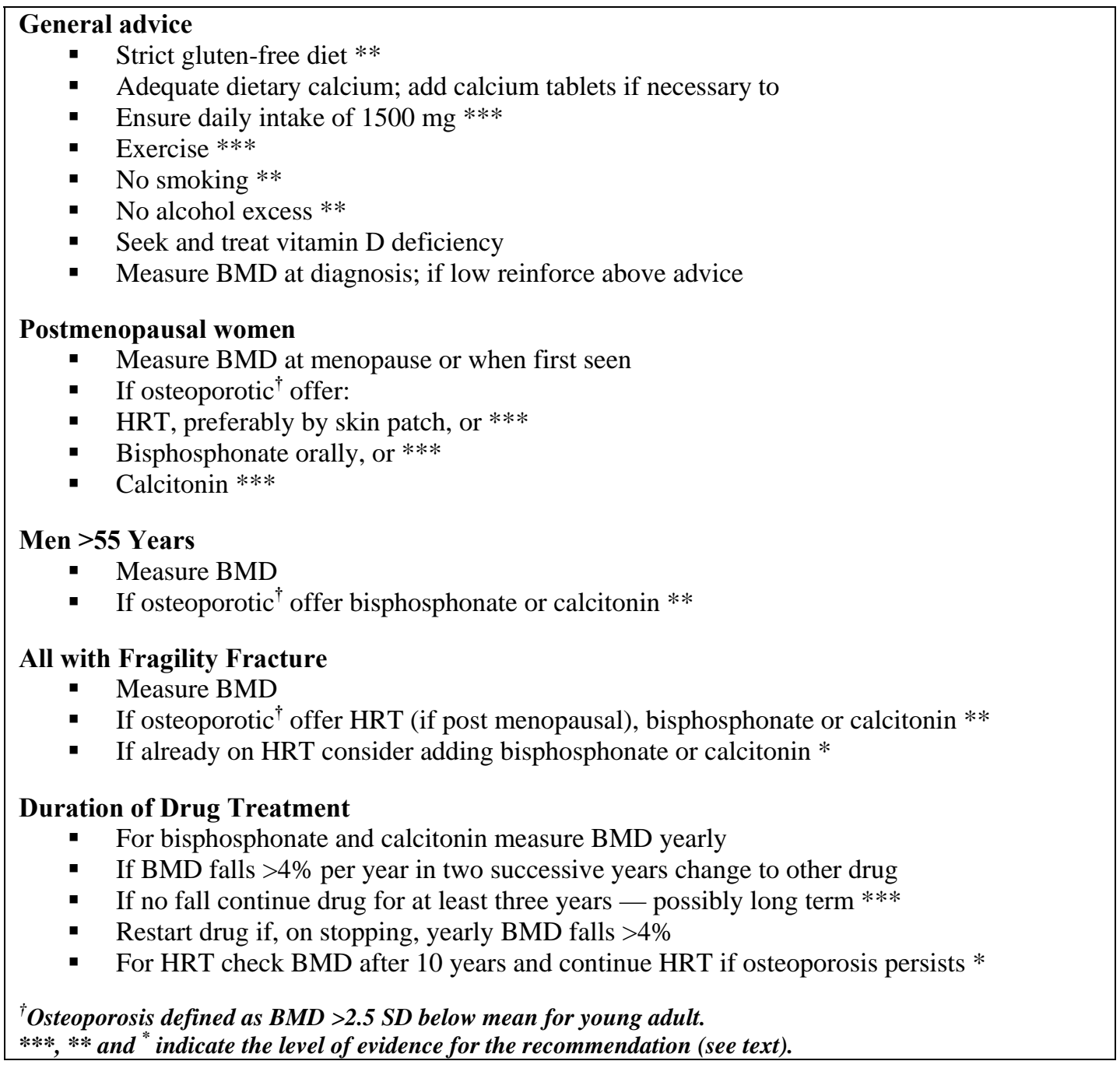




\section{RESULTS:}

Total of 73 patients were enrolled for retrospective analysis. Of them 44 were females and 29 were males. Average age of the female patients was 49 years and of male patients were 42. Age wise distribution of the patients enrolled in the study is shown in Table 2.

Total of 54 patients underwent DEXA scan at the diagnosis and 15 (27.3\%) were found to be Osteoporotic at presentation. Amongst the patients detected to have osteoporosis, 9 (60\%) were females and 6(40\%) were males. Age distribution of the patients detected to have osteoporosis is shown in the Table 3.

Subsequent course of the treatment of these patients was also analysed in this retrospective analysis irrespective of whether they were osteoporotic or not. The remaining 39 patients who were found to be free from osteoporosis, during the initial DEXA scan were also followed up. The entire duration of the follow up consisted of DEXA scans every 2years. Of these patients 13(33\%) were detected to have osteoporosis on the subsequent scan. On the subsequent DEXA scan, only 1 patient was found to have worsening of osteoporosis, though without a fracture and the treatment was modified in keeping with the suggested guidelines and needs future DEXA scans. Amongst the rest of 12 patients, 8(75\%) had improvement in the BMD on the DEXA scan, which was helped by the strict adherence to the gluten free diet.

Table 2: Age distribution of subjects enrolled in the study

\begin{tabular}{|c|c|c|c|c|}
\hline \multirow{2}{*}{ Age group } & \multicolumn{2}{|c|}{ Male } & \multicolumn{2}{c|}{ Female } \\
\cline { 2 - 5 } & No. & $\%$ & No. & $\%$ \\
\hline Less than 36 years & 09 & 35 & 05 & 11 \\
\hline 36-52 years & 10 & 33 & 20 & 40 \\
\hline 53-72 years & 09 & 32 & 17 & 38 \\
\hline More than 72 years & 01 & 03 & 05 & 11 \\
\hline Total & 29 & 100 & 44 & 100 \\
\hline
\end{tabular}

Table 3: Age distribution of the patients having osteoporosis

\begin{tabular}{|c|c|c|c|}
\hline Age group & Male & Female & Total \\
\hline Less than 35 years & 01 & 00 & 01 \\
\hline 36-53 years & 01 & 05 & 06 \\
\hline 54-72 years & 04 & 04 & 08 \\
\hline More than 72 years & 00 & 00 & 00 \\
\hline Total & 06 & 09 & 15 \\
\hline
\end{tabular}

\section{DISCUSSION:}

It is important to recognise that osteoporosis is but one of a number of factors predisposing to fracture, just as a raised cholesterol and diastolic pressure are each just one of many factors predisposing to coronary artery disease. ${ }^{4}$ Awareness of surroundings, mobility, and eyesight collectively contribute to a tendency to fall and all are likely to be important. ${ }^{16}$ Furthermore, bone strength is largely related to trabecular structure, certainly in the proximal femur, whereas BMD is a composite measurement of both cortical and trabecular bone. ${ }^{17}$ Although the population can be stratified for fracture risk using BMD measurements, its poor sensitivity for predicting actual fracture makes it unsuitable for screening the whole population or even all post-menopausal women - the difficulties and costs are great and it would have only a small contribution to fracture prevention in the community as a

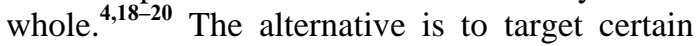
high risk groups for screening or treatment, or both. The evidence for reduced BMD in coeliac disease is good. ${ }^{\mathbf{5}-13}$ One study ${ }^{\mathbf{1 9}}$ showed that $47 \%$ of women and $50 \%$ of men on a gluten-free diet had osteoporosis defined as BMD more than 2 SD below mean peak bone mass measured by DEXA. The BMD was positively related to calcium intake, body mass index (BMI) and menopausal age. Other studies have shown significant improvement one year after starting a gluten-free diet, ${ }^{21}$ normal BMD in patients who had been on a gluten-free diet since childhood, ${ }^{\mathbf{1 5}}$ and improved bone mineralization on a glutenfree diet in childhood and adolescence ${ }^{.22}$ The 
incidence of fractures in coeliac disease is not known but there is no reason to suppose that the reduction in BMD is less predictive of fracture risk than in the general population. ${ }^{4}$ The abstract of one study ${ }^{23}$ reported a significantly higher proportion of patients with a history of fracture than controls (21\% v 3\%). The mean age was 52 years and there was no relation between fracture and BMD.

The reasonable explanation of the fact that only 54 out of total 73 patients did not undergo the DEXA scan at diagnosis, is that these patients have been enrolled from the early 80's, and then there were no evidence for the screening every patient with coeliac disease for osteoporosis, and hence in the light of recent research and evidence we were compelled to change the present practise which I presume will help maintain healthy bones in the coeliac disease community and will reduce the associated morbidity and the cost to the healthcare system.

\section{CONCLUSION:}

This retrospective analysis reemphasises the fact that there is increased risk of osteoporosis in the patients who suffer from coeliac disease, and it predisposes these patients with fairly early onset of osteoporosis .Therefore screening and following them up, in the light of recent evidence for the presence and progression of it, is advisable and beneficial to the patients in the long term.

\section{LIST OF ABBREVIATIONS:}

DEXA- Dual energy X-ray Absorptiometry, BMD- Bone Mineral Density and HRTHormone Replacement Therapy.

\section{REFERENCES:}

1. Scott BB, Scott EM, Gaywood I. Eur J Gastroenterol Hepatol 1998 Aug;10(8):689-98.

2. Togerson D, Iglesias C and Reid DM, The effective management of osteoporosis. In the economics of fracture prevention, Edited by Barlow DH, Francis RM and Miles A 2001;111-121.

3. McGough N, Cummings JH. Coeliac disease: a diverse clinical syndrome caused by intolerance of wheat, barley and rye. Proc Nutr Soc. 2005 Nov;64(4):434-50.

4. Scott EM, Gaywood I, Scott BB. Guidelines for osteoporosis in Coeliac disease and inflammatory bowel disease, British Society of Gastroenterology, 2002.
5. Caraceni MP, Molteni N, Bardella MT, et al. Bone and mineral metabolism in adult celiac disease. Am J Gastroenterol 1988;83:274-7.

6. Molteni N, Caraceni MP, Bardella MT, et al. Bone mineral density in adult celiac patients and the effect of gluten-free diet from childhood. Am J Gastroenterol 1990;85:513.

7. Bode S, Hassager C, Gudmand-Hoyer E, et al. Body composition and calcium metabolism in adult treated coeliac disease. Gut 1991;32:1342-5.

8. Mazure R, Vasquez H, Gonzalez D, et al. Bone mineral affection in asymptomatic adult patients with celiac disease. Am J Gastroenterol 1994;89:2130-4.

9. Valdimarsson T, Toss G, Ross I, et al. Bone mineral density in coeliac disease. Scand $J$ Gastroenterol 1994;29:457-61.

10. McFarlane XA, Bhalla AK, Reeves DE, et al. Osteoporosis in treated adult coeliac disease. Gut 1995;36:710-14.

11. Walters JRF, Banks LM, Butcher GP, et al. Detection of low bone mineral density by dual energy absorptiometry in unsuspected suboptimally treated coeliac disease. Gut 1995;37:220-4.

12. Pistorius LR, Sweiden WH, Purdie DW, et al. Coeliac disease and bone mineral density in adult female patients. Gut 1995;37:63942.

13. Corazza GR, Sario AD, Cecchetti L, et al. Bone mass and metabolism in patients with celiac disease. Gastroenterology 1995;109:122-8.

14. WHO Study Group on Assessment of Fracture Risk and its Application to Screening for Post Menopausal Osteoporosis. Assessment of fracture risk and its application to screening for post menopausal osteoporosis: report of a WHO study group. (WHO technical series 843.) Geneva: WHO, 1994.

15. Melton LJ, Atkinson EJ, O’Fallon WM, et al. Long-term fracture risk prediction with bone mineral measurements made at various skeletal sites? J Bone Miner Res 1991;6(suppl 1):136.

16. Porter RW, Miller CG, Grainger D, et al. Prediction of hip fracture in elderly women: a prospective study. BMJ 1990; 301:638-41.

17. Lotz JC, Gerhart TN, Hayes WC. Mechanical properties of trabecular bone from the proximal femur: a quantitative CT 
study. $J$ Comput Assist Tomogr 1990;14:107-14.

18. Marshall D, Johnell O, Wedel H. Metaanalysis of how well measures of bone mineral density predict occurrence of osteoporotic fractures. BMJ 1996;312:12549.

19. Anonymous. Screening for osteoporosis to prevent fractures: bulletin on the effectiveness of health services intervention for decision makers. Vol 1. London School of Public Health, University of Leeds, Centre for Health Economics, University of York, Research Unit of the Royal College of Physicians, Department of Health, 1992.
20. Sheldon TA, RaZe A,Watt I. Department of Health shoots itself in the hip. BMJ 1996;312:296-8.

21. Valdimarsson T, Lofman O, Toss G, et al. Reversal of osteopenia with diet in adult coeliac disease. Gut 1996;38:322-7.

22. Mora S, Weber G, Barera G, et al. Effect of gluten-free diet on bone mineral content in growing patients with celiac disease. Am $J$ Clin Nutr 1993;57:224-8.

23. McFarlane XA, Dixey J, Dumfrey J, et al. Increased risk of bone fractures in coeliac disease [abstract]. Gastroenterology 1996;110:821.

24. van Staa TP, Dennison EM, Leufkens HG and Cooper C. Epidemiology of fractures in England and Wales. Bone 2001;29:517-22.

Internet Journal of Medical Update

ISSN 1694-0423, http://www.geocities.com/agnihotrimed 